\title{
Knowledge and preventive practices of livestock farmers on infectious causes of reproductive disorders in dairy cows in the Kembata Tambaro zone, southern Ethiopia
}

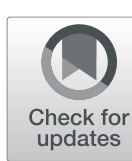

Birhanu Ayele ${ }^{1 *}$ and Samson Leta ${ }^{2}$

\begin{abstract}
Several studies in Ethiopia have shown a high prevalence of reproductive disorders (RDs) in dairy cows. However, there is a lack of information about the levels of knowledge among farming community about the causes associated with RDs. A questionnaire-based cross-sectional study design was administered to 278 livestock farmers (LFs) in the Kembata Tambaro zone to evaluate knowledge and preventive practices on infectious causes of RDs in dairy cows. The results show that almost all farmers had heard about RDs, but more than half did not realize that reproductive system infections (RSIs) could cause RDs in dairy cows. A significant number of participants were not aware of the spread of RSIs between animals through sharing of breeding bulls, ingestion of urine contaminated feed, unhygienic management, sharing of equipment between milking cows, and interactions with contagious animals. The majority of LFs reported that they frequently consulted with traditional healers regarding the treatment of RDs, but very few looked for veterinary assistance. The results of multivariable logistic regression analysis showed that level of education and living areas were factors significantly and positively associated with knowledge about RSIs. Likewise, occupation, level of education and being knowledgeable about RSIs were significantly associated with good preventive practices. Veterinarians and responsible authorities should take these results into consideration to educate farmers on preventing losses attributed to RSIs.
\end{abstract}

Keywords: Dairy cows, RSIs, Livestock farmers, Knowledge, Preventive practices

\section{Background}

Ethiopia holds large potential for dairy development due to its large livestock population and the favorable climatic conditions for improved, high-yield animal breeds (Ahmed et al. 2004). The country currently manages the largest livestock population in Africa, estimated at 65.35 million cattle, 39.9 million sheep, and 50.5 million goats (CSA 2020). There are approximately 12 million dairy cows in Ethiopia producing an average of approximately

\footnotetext{
* Correspondence: birayele@gmail.com

'Department of Animal Science, Wachemo University Durame Campus, Durame, Ethiopia

Full list of author information is available at the end of the article
}

$1.48 \mathrm{~L}$ milk per cow per day over a lactation period of seven months (CSA 2020). Regarding breed types, the majority $(97.8 \%)$ of the total cattle in the country are local breeds, whereas hybrid and exotic breeds accounted for approximately $1.91 \%$ and $0.32 \%$, respectively (CSA 2020).

The reproductive performance of modern dairy cows globally has decreased over the past 50 years (Softic et al. 2020). This scenario is further exacerbated due to the emphasis on the selection and rearing of animals for specific commercial purposes, which compromises livestock reproduction (Yoo 2010). Reproductive system infections, either specific or nonspecific, significantly 
account for reproductive underperformances in dairy cows worldwide (Rosales and Ametaj 2021). Diseases such as brucellosis, leptospirosis, infectious bovine rhinotracheitis (IBR), bovine virus diarrhea (BVD), and vibriosis are known to reduce reproductive capabilities in dairy cows (Radostits et al. 2007; Rosales and Ametaj 2021). These diseases are not only related to the prosperity of livestock industry but also important for public health (World Bank 2010; Ettinger et al. 2017; Radostits et al. 2007).

Bovine brucellosis caused by Brucella abortus bacteria is responsible for severe economic losses in the livestock industry. It causes abortions in female cattle and infertility in males (Rosales and Ametaj 2021). The most common route of infection is the digestive tract, through ingestion of feed or water contaminated with the bacteria. As bacteria have an affinity for the reproductive tract, abortions, infertility, retained placenta, and birth to weak calves frequently occur in dairy herds following disease incidence. Brucellosis can also have severe public health impacts because of its zoonotic potential (World Bank 2010; Ettinger et al. 2017; Hussien 2019; Radostits et al. 2007; Yoo 2010). Leptospirosis is an economically important bacterial infection that can affect several species, including cattle, sheep, horse, dog, pig, wildlife and human. The disease can cause abortions, low-grade uterine infections, mastitis, repeat breeding, and occasionally systemic infection. The infection is spread mainly when a susceptible animal is in contact with the urine of infected animals or aborted fetuses (Hussien 2019; Radostitis et al. 2000; Yoo 2010). IBR and BVD complexes are virus-induced diseases that cause a wide variety of clinical syndromes in cattle, including infertility, respiratory disease (pneumonia), congenital abnormalities (eye and/ or brain defects), abortion, and stillbirths (Ettinger et al. 2017; Hussien 2019; Overbay 1999; Yoo 2010). Vibriosis is a venereal disease of cattle caused by the bacterium Campylobacter fetus and is spread by infected bulls when they mate susceptible cows and heifers. The disease results in infertility and, occasionally, abortion in cattle (Ettinger et al. 2017; Hussien 2019; Radostitis et al. 2000; Yoo 2010).

Although smallholder dairy farming significantly enhances the livelihoods of farmers in the Kembata Tambaro zone (Ayele et al. 2016a; Ayele et al. 2016b; Mitiku 2018), productivity is constrained by several factors, of which reproductive disorders (RDs) are the most important (Mitiku 2017). A recent study provided information on the most challenging problems for dairy farmers, such as repeat breeding syndrome, dystocia, retained fetal membrane, metritis complex, abortion, uterine prolapse, and stillbirth, in their order of importance. The study also investigated Brucella bacteria from the serum of sampled cows, suggesting that it is responsible for the precipitation of the major reproductive health problems of the area (Mitiku 2017).

Good cooperation between livestock farmers (LFs), veterinarians and other organizations involved in livestock production is essential to implement specific strategies to mitigate the risk of disease transmission (Jansen et al. 2010; Yoo 2010). Additionally, an evaluation of the farming community's awareness of the likely causes of RDs could help in designing and implementing effective disease prevention and control strategies at the farm and household levels. Hence, this study was conducted with the aim of evaluating LFs' knowledge on RDs with a focus on infectious causes and their preventive practices in the Kembata Tambaro zone of southern Ethiopia.

\section{Results}

\section{Sociodemographic characteristics}

Table 1 summarized the sociodemographic characteristics of respondents. Out of the total interviewed respondents $(n=278)$, the majority $(62.2 \%)$ were in age range of $38-57$ years, with a mean age of $43.3 \pm 12$. Over three quarters $(78 \%)$ were males, $65.8 \%$ were rural dwellers, and more than half (53.6\%) were engaged with farming. Totally 135 respondents (48.6\%) received at least primary school education.

Table 1 Sociodemographic characteristics of the respondents

\begin{tabular}{ll}
\hline Characteristics & Value \\
\hline Age, year, $\mathbf{n}$ (\%) & $\mathbf{4 3 . 3 \pm 1 2}$ \\
$23-37$ & $36(13)$ \\
$38-57$ & $173(62.2)$ \\
$58-77$ & $69(24.8)$ \\
Sex, $\mathbf{n}$ (\%) & \\
Male & $217(78)$ \\
Female & $61(22)$ \\
Current address, $\mathbf{n}$ (\%) & $183(65.8)$ \\
Rural & $95(34.2)$ \\
Urban & \\
Occupation, $\mathbf{n}$ (\%) & $149(53.6)$ \\
Farmer & $57(20.5)$ \\
Trader & $46(16.6)$ \\
Government employee & $7(2.5)$ \\
NGO worker & $19(6.8)$ \\
Others (driver, preacher, and broker) & \\
Level of education, $\mathbf{n}$ (\%) & $143(51.4)$ \\
No formal education & $86(31)$ \\
Primary school & $19(6.8)$ \\
High school & $30(10.8)$ \\
College or above & \\
\hline
\end{tabular}

Notes: NGO Nongovernment organization, $n$ Number of respondents 


\section{Knowledge and preventive practices of LFs on reproductive system infections (RSIs)}

Respondents' knowledge and preventive practices relating to RDs is described in Table 2. Nearly all (96.8\%) respondents had heard about RDs in dairy cows, and over $60 \%(63.5 \%)$ perceived that RDs affect dairy cow productivity. Nevertheless, the majority (60\%) did not perceive that microorganisms could cause RDs in dairy cows. Similarly, a large number of respondents were not conscious about the transmission mechanisms of RSIs between animals, such as hiring or sharing of breeding bulls (63\%); ingestion of urine-contaminated feed (73\%); sharing of equipment between milking cows (67\%); and interaction with contagious animals (62\%).

Additionally, over 90\% (93.3\%) respondents did not realize that animals with RSIs could show symptoms of respiratory illness (pneumonia), and 203 (75.5\%) were not aware of the manifestation of congenital abnormalities at calving in pregnant cows following RSIs.

Although the majority $(62.5 \%)$ of respondents in the present study understood that humans can get an infection from animals, and 186 (69\%) believed that collecting the aborted fetuses and fetal membrane with bare hands could expose them to RSIs; only 17 (6.3\%) used gloves during calving assistance, and less than half (46.5\%) used gloves during the management of aborted fetuses and fetal membranes. In addition, the majority of respondents had the habit of drinking unpasteurized milk (82\%) and eating raw meat (62\%).

Regarding the prevention of RSIs, only a small percentage of LFs had employed appropriate disease prevention practices at their farms, such as the selection of sires with low percent stillbirth/abortion (24.5\%), keeping cows in a clean and dry shed (32.3\%), avoiding mixing of diseased cows with healthy ones (13\%), and avoiding off-farm bedding materials (7.8\%). Additionally, only 91 (33.8\%) of respondents had vaccinated their animals during the past year (the year preceding the start of this study) despite their vets' advice. The majority (63\%) preferred traditional (herbal remedies) to modern (veterinary treatment) to treat RDs.

Overall, less than half (31.59\%) [95\% CI: (28.09\%$35.32 \%)]$ of LFs in the present study had good knowledge of RSIs in dairy cows, and $32.17 \%$ [95\% CI: $(28.28 \%-36.32 \%)]$ had good preventive practices.

\section{Factors associated with knowledge and preventive practices of LFs on RSIs}

The results of multivariable logistic regression analysis showed that urban participants were over three times $[\mathrm{OR}=3.34 \quad(95 \%$ CI $1.73-6.61)]$ more likely to be knowledgeable than rural participants, and the difference was statistically significant $(P<0.05)$. Additionally, livestock farmers who had a minimum of primary school education were more knowledgeable $[\mathrm{OR}=2.33$ (95\% CI 0.35-4.58)] than farmers who had no formal education (Table 3).

In this study, preventive practices of respondents were evaluated by occupation, level of education, and their knowledge of RSIs. The results, therefore, indicated that government employees had over four times $[\mathrm{OR}=4.13$ (95\% CI 2.22-12)] better preventive practices than farmers, and traders had nearly three times $[\mathrm{OR}=2.85$ (95\% CI 0.52-5.35)] better preventive practices than farmers. Likewise, respondents who had a minimum of primary school education had over four times [OR = 4.43 (95\% CI 22.22-11.5)] better preventive practices than respondents with no formal education. Knowledgeable participants had nearly three times $[\mathrm{OR}=2.75$ (95\% CI 1.36-5.65)] better preventive practices than non-knowledgeable participants (Table 3).

\section{Discussion}

To the best of our knowledge, this is the first study attempting to describe the knowledge and preventive practices of LFs on the infectious cause of RDs in dairy cows in the Kembata Tambaro zone. In this study, nearly all participants were aware of RDs in dairy cows, which is in line with the results reported in India (Subhash et al. 2013). Additionally, more than half respondents perceived that RDs affect dairy cow productivity. The respondents' insight agrees with reports in veterinary literature that report severe economic losses in dairy herds following incidences of RDs, such as slower uterine involution, prolonged interconception and calving interval, reduced reproduction rate, drop in milk production, and increased cost of medication (Abutarbush 2010; Ettinger et al. 2017; Radostits et al. 2007; Rosales and Ametaj 2021).

In this study, more than half respondents did not perceive that RSIs could cause RDs in dairy cows. Additionally, considerable numbers were not aware of symptoms of RSIs and the likely transmission mechanisms. The low awareness of respondents could be attributed to a lack of adequate understanding of livestock diseases and the low proportion of farmers that received formal education in the study area, which is in agreement with the study report in Pakistan (Arif et al. 2017). Similarly, in the present study, fewer respondents were aware about the risk of transmission of any disease from animals to humans, which is in line with the findings in Ethiopia (Legesse et al. 2018; Zewdie et al. 2018) and elsewhere (Ndengu et al. 2017; Zhang et al. 2019). This suggested that improving LFs' knowledge on animal disease and the likely modes of transmission could help to reduce disease risk in humans.

Previous studies have demonstrated that improving LFs' awareness of livestock diseases and preventive herd 
Table 2 Knowledge and preventive practices of LFs on infectious causes of reproductive disorders in dairy cows in the Kembata Tambaro zone, southern Ethiopia ( $n=278$ farmers)

\begin{tabular}{|c|c|c|c|}
\hline \multirow[t]{2}{*}{ No } & \multirow[t]{2}{*}{ Knowledge } & \multicolumn{2}{|c|}{ n (\%) } \\
\hline & & Yes (\%) & No $(\%)$ \\
\hline K1 & Heard about RDs in dairy cows & $269(96.8)$ & $9(3.2)$ \\
\hline K2 & RDs affect dairy cow productivity & $171(63.5)$ & $98(36.5)$ \\
\hline K3 & RSIs could cause RDs in dairy cows & $111(40)$ & $167(60)$ \\
\hline \multirow[t]{7}{*}{ K4 } & Opinion of LFs on RSIs as cause for RDs: & & \\
\hline & Abortion and/or stillbirth & $47(17.5)$ & $222(82.5)$ \\
\hline & Anoestrus & $2(0.7)$ & $267(99.3)$ \\
\hline & Repeat breading syndrome & $6(2.2)$ & $263(97.8)$ \\
\hline & Retained fetal membrane & $10(3.7)$ & $279(96.3)$ \\
\hline & Dystocia & $6(2.2)$ & $263(97.8)$ \\
\hline & Prolapse & $40(15)$ & $229(85)$ \\
\hline K5 & Sires/breeding bulls can be affected by RSIs & $145(54)$ & $124(46)$ \\
\hline K6 & Hiring/sharing breeding bulls can disseminate RSIs & $100(37)$ & $169(63)$ \\
\hline K7 & Ingestion of urine contaminated feeds can transmit RSIs & $73(27)$ & $196(73)$ \\
\hline K8 & Sharing of equipment between milking cows can disseminate RSIs & $89(33)$ & $180(67)$ \\
\hline K9 & RSIs is contagious (can be transmitted between animals) & $102(38)$ & $167(62)$ \\
\hline K10 & Respiratory disease (pneumonia) could be the sign of RSIs & $18(6.7)$ & $251(93.3)$ \\
\hline K11 & $\begin{array}{l}\text { Congenital abnormalities (like eye and brain defects) } \\
\text { could be the sign of RSIs }\end{array}$ & $66(24.5)$ & $203(75.5)$ \\
\hline $\mathrm{K} 12$ & $\begin{array}{l}\text { Disposing aborted fetuses and fetal membranes into the environment could } \\
\text { contribute to the spread of RSIs between animals }\end{array}$ & $153(57)$ & $116(43)$ \\
\hline K13 & Humans can get any infection from animals & $136(62.5)$ & $133(49.5)$ \\
\hline K14 & $\begin{array}{l}\text { Collecting the aborted fetuses and fetal membrane with bare hands can } \\
\text { expose humans to RSIs }\end{array}$ & $186(69)$ & $83(31)$ \\
\hline K15 & Eating uncooked meat and/or drinking of raw milk could expose humans to RSIs & $91(33.8)$ & $178(66.2)$ \\
\hline K16 & Hygienic management can prevent RSIs in dairy cows & $153(57)$ & $116(43)$ \\
\hline \multirow[t]{2}{*}{ K17 } & Vaccination is an effective way to prevent disease in animals & $137(51)$ & $132(49)$ \\
\hline & Preventive practices & Agree (\%) & Disagree (\%) \\
\hline P1 & I do not hire/share breeding bulls & $89(33)$ & $180(67)$ \\
\hline P2 & I select sires with low percent stillbirth/abortion & $66(24.5)$ & $203(75.5)$ \\
\hline P3 & I avoid sharing calving spaces with other animals & $101(37.5)$ & $168(62.5)$ \\
\hline P4 & I use gloves during calving assistance & $17(6.3)$ & $252(93.7)$ \\
\hline P5 & I use gloves during handling of aborted fetuses and fetal membranes & $125(46.5)$ & $144(53.5)$ \\
\hline P6 & I remove aborted fetuses and fetal membrane immediately after passing & $180(67)$ & $89(33)$ \\
\hline P7 & I always keep cows in a clean and dry shed & $87(32.3)$ & $182(67.7)$ \\
\hline P8 & I avoid mixing of diseased cows with healthy ones & $35(13)$ & $234(87)$ \\
\hline P9 & I disinfect calving place and calving assistance' equipment & $118(44)$ & $151(56)$ \\
\hline P10 & I maintain adequate feeding per cows & $102(38)$ & $167(62)$ \\
\hline P11 & I always avoid off-farm bedding materials & $21(7.8)$ & $248(92.2)$ \\
\hline P12 & I don't eat raw/uncooked meat & $102(38)$ & $167(62)$ \\
\hline P13 & I don't drink raw/unpasteurized milk & $48(18)$ & $221(82)$ \\
\hline P14 & I always participate in animal health trainings & $102(38)$ & $167(62)$ \\
\hline P15 & I always vaccinate animals based on vet's advice & $91(33.8)$ & $178(66.2)$ \\
\hline P16 & I consult with veterinarian regarding treatment of RDs & $100(37)$ & $169(63)$ \\
\hline
\end{tabular}


Table 3 Factors associated with knowledge and preventive practices of LFs on RSIs in the Kembata Tembaro zone ( $n=269$ farmers)

\begin{tabular}{|c|c|c|c|c|c|c|c|}
\hline \multirow[t]{2}{*}{ Variables and categories } & \multirow[t]{2}{*}{ Total, n (\%) } & \multicolumn{2}{|c|}{ Knowledge on RSIs } & \multirow[b]{2}{*}{ OR 95\% Cl } & \multicolumn{2}{|c|}{ Preventive practice } & \multirow[b]{2}{*}{ OR $95 \% \mathrm{Cl}$} \\
\hline & & $\begin{array}{l}\text { Knowledgeable, } \\
\text { n (\%) }\end{array}$ & $\begin{array}{l}\text { Not knowledgeable, } \\
\text { n (\%) }\end{array}$ & & $\begin{array}{l}\text { Good, } \\
\text { n (\%) }\end{array}$ & $\begin{array}{l}\text { Not good, } \\
\text { n (\%) }\end{array}$ & \\
\hline \multicolumn{8}{|l|}{ Age } \\
\hline $23-37$ & $34(12.6)$ & $11(4.1)$ & $23(8.5)$ & 1 & & & \\
\hline $38-57$ & $166(61.7)$ & $48(17.8)$ & $118(43.9)$ & $1.03(1.31-3.35)$ & & & \\
\hline $58-77$ & $69(25.7)$ & $26(9.7)$ & $43(16)$ & $1.18(0.22-5.27)$ & & & \\
\hline \multicolumn{8}{|l|}{ Sex } \\
\hline Male & $208(77)$ & $64(23.5)$ & $144(53.5)$ & 1 & $37(13.4)$ & $171(63.6)$ & 1 \\
\hline Female & $61(23)$ & $21(8.1)$ & $40(14.9)$ & $0.75(0.57-1.29)$ & $50(18.6)$ & $11(4.4)$ & $0.77(0.3-3.9)$ \\
\hline \multicolumn{8}{|l|}{ Current address } \\
\hline Rural & $178(66)$ & $60(22.2)$ & $118(43.8)$ & 1 & $51(19)$ & $127(47)$ & 1 \\
\hline Urban & $91(34.2)$ & $25(9.7)$ & $66(24.5)$ & $3.34(1.73-6.61)^{*}$ & $36(13.4)$ & $55(20.8)$ & $0.95(0.17-3.34)$ \\
\hline \multicolumn{8}{|l|}{ Occupation } \\
\hline Farmer & $146(54)$ & $51(19)$ & $95(35)$ & 1 & $47(17.5)$ & $99(36.5)$ & 1 \\
\hline Trader & $57(21.2)$ & $16(5.9)$ & $41(15.3)$ & $2.08(1.44-6.32)$ & $11(4.2)$ & $46(17)$ & $2.85(0.52-5.35)^{*}$ \\
\hline Government employee & $44(16.4)$ & $13(4.8)$ & $31(11.6)$ & $3.51(1.35-8.75)$ & $22(8.2)$ & $22(8.2)$ & $4.13(2.22-12)^{*}$ \\
\hline NGO worker & $6(2.2)$ & $4(1.5)$ & $2(0.7)$ & $1.02(0.06-4.43)$ & $4(1.5)$ & $2(0.7)$ & $1.56(1.15-7.25)^{*}$ \\
\hline $\begin{array}{l}\text { Others (driver, preacher, and } \\
\text { broker) }\end{array}$ & $16(6.4)$ & $1(0.4)$ & $15(6)$ & $0.75(0.51-1.16)$ & $3(1.1)$ & $13(5.3)$ & $1.08(0.25-6.33)$ \\
\hline \multicolumn{8}{|l|}{ Degree of education } \\
\hline No formal education & $138(51.3)$ & $32(11.9)$ & $106(39.4)$ & 1 & $34(12.6)$ & $104(38.7)$ & 1 \\
\hline$\geq$ Primary school & $131(48.7)$ & $53(19.7)$ & $78(29)$ & $2.33(0.35-4.58)^{*}$ & $53(19.7)$ & $78(29)$ & $4.43(2.22-11.5)^{*}$ \\
\hline \multicolumn{8}{|l|}{ Knowledge on RSIs } \\
\hline Not knowledgeable & $184(68.4)$ & & & & $38(14)$ & $146(54.4)$ & 1 \\
\hline Knowledgeable & 85 (31.6) & & & & 49 (18.2) & $36(13.4)$ & $2.75(1.36-5.65)^{*}$ \\
\hline
\end{tabular}

Notes: *, Significant at $P<0.05$. NB, knowledge and preventive practices were assessed only for 269 LFs who perceived that RSIs could cause RDs in dairy cows

management practices could help to alleviate disease transmission risk and increase animal productivity (Ettinger et al. 2017; Radostitis et al. 2000; Roberts 1971; Sprott and Robert 2012; Yoo 2010). Although many respondents in the present study had an awareness of the impact of RSIs in dairy cows, the majority were involved in practices that could create a conducive environment for the transmission of disease between animals and, most importantly, to humans. For example, two-third of the respondents had hired/shared breeding bulls, and they were unaware of the transmission risk of RSIs from bulls to cows. The respondents' practice was contrary to remarks in the veterinary literature that described the likely transmission of RSIs such as brucellosis, vibrosis, IBR, BVD and trichomoasis between animals through natural mating (Ettinger et al. 2017; Radostitis et al. 2000; Roberts 1971; Sprott and Robert 2012; Yoo 2010).

Similarly, the majority of respondents reported sharing of calving space with other animals, and a study by Diez and Coelho 2013 showed the importance of this practice for disease transmission between animals. Many RSIs can be shed during calving or at abortion, contaminating the environment and increasing the risk of disease transmission to other animals and humans (Ettinger et al. 2017; Hussien 2019; Radostits et al. 2007; Rosales and Ametaj 2021).

In relation to practices that cause disease transmission from animals to humans, consumption of raw milk (Velázquez-Ordoñez et al. 2019) and meat (van Bree et al. 2018) have been previously described as the riskiest practice. In the present study, the majority of respondents reported that they consumed raw milk and meat on a regular basis, suggestive of a higher risk of zoonosis if the disease was present in their herd. Awareness is needed to improve the respondents' behavior related to improving animal health to mitigate the disease risk, not only for the sake of their animals' health and welfare but also to protect humans from zoonotic pathogens (Abutarbush 2010; Ettinger et al. 2017; Rosales and Ametaj 2021; Velázquez-Ordoñez et al. 2019).

Opinions of LFs on the treatment of RDs revealed that the majority preferred traditional (herbal remedies) to 
modern (veterinarian services). Respondents perceived that the causes for most of RDs in dairy cows were different from microorganisms, and they thought traditional remedies/practices were effective therapy to resolve the problem in affected animals. For example, a significant number of respondents believed physical obstructions of female genitalia were a cause of anoestrus in dairy cows, and they perceived bleeding or removal of obstructions as an appropriate treatment. There are traditional healers that were recognized by the community that livestock farmers used to consult in this regard. Similarly, according to LFs' belief, the causes for repeat breading syndromes, retained fetal membranes, and dystocia are gene merit from parents, poor feeding practices, and bad weather conditions, respectively. It is unclear why farmers focus mainly on a traditional approach to manage the abovementioned problems. However, complete ignorance of modern treatment in this case would miss infectious agents that cause similar symptoms to become untreated. This, in turn, could worsen the problem in infected dairy herds.

In this study, we observed that urban participants were more aware of RSIs than rural participants. This might be because in urban areas, accessibility to animal health professionals and veterinary clinics was high. This study also confirmed that the level of education was associated with knowledge of RSIs and preventive practices in relation to these diseases. Participants with no formal education were less likely to be aware of RSIs than those with a minimum primary school education. The better awareness among respondents with a minimum of primary school education could be due to the inclusion of livestock health education in the formal education system, which is in agreement with the study report in Pakistan (Arif et al. 2017).

Additionally, in this study, livestock farmers, drivers, preachers and brokers were less likely to have good preventive practices toward RSIs than government employees and Nongovernment organization (NGO) workers. Respondents with no formal education were less likely to have good preventive practices at their farms, putting themselves at more risk of contracting RSIs. Similarly, respondents who were knowledgeable about RSIs had a lower risk practice.

In conclusion, this reaearch demonstrated a poor understanding of RSIs among the farming communities in the study area. Practices at both farm and household levels are risky and could potentially contribute to disease transmission to humans. A significant number of respondents presented different and unsubstantiated cultural beliefs about the causes and treatment of RSIs. These cultural beliefs need to be considered in relation to any educational intervention program (Arif et al. 2017). Poor knowledge on livestock disease, inappropriate perceptions, and practices toward the management of these diseases strongly justify the need for health education among LFs in the Kembata Tembaro zone. In light of these findings, little attempt had been made to train livestock farmers as of the present study, and very few farmers had received training related to primary animal healthcare according to the Livestock and Fishery Agency reports of the Kembata Tembaro zone. Farmers who received primary animal health care training witnessed from their own assessment that disease incidences had been reduced on their farms and milk production was improved after the trainings, which is in agreement with the findings in Uganda (Cecilia et al. 2019; Vaarst et al. 2007). Hence, for low-income countries such as Ethiopia, 1) where the economy is mostly dependent on agriculture (World Bank 2010; McDermott and Grace 2012), 2) where over threequarters of households have direct contact with domestic animals, 3) where there is a lack of coordination among human and animal health sectors, and 4) where there are inadequate resources for public health systems, targeted and culturally appropriate health education is crucial to increase the awareness of farmers not only on RSIs but also on other zoonotic diseases (Arif et al. 2017).

\section{Conclusions}

This study showed that LFs had poor knowledge about RSIs and poor preventive practices at farm and household levels, all contributing to the risk of humans contracting the diseases. Respondents' knowledge about RSIs is mainly associated with education and their residence. Moreover, providing knowledge to respondents about RSIs might be useful in improving some of the farmers' preventive practices. Therefore, awareness creation programs should be designed to improve farmers' knowledge of livestock disease to increase the adoption of preventive practices and minimize losses attributed to disease incidences.

\section{Methods}

\section{Description of the study area}

This study was conducted in the Kembata Tambaro zone of the Southern Nations, Nationalities and Peoples' Region (SNNPR). The Kembata Tambaro zone is located at altitudes between 501 and $3058 \mathrm{~m}$ above sea level with an annual rainfall of approximately $800-1200 \mathrm{~mm}$ and temperature ranging from $30.7-37^{\circ} \mathrm{C}$. The zone has 8 districts, 4 administrative towns, and 118 rural and 17 urban PAs. Farmers generally practice mixed crop livestock production. The estimated livestock population of the zone is 812,175 cattle (composed of 575,020 local zebus and 237,155 crossbred), 255,003 sheep, 195,280 goats, 72,657 equines, $1,373,784$ poultry, and 32,640 bee 
colonies. A total of $116,612.45$ tons of milk is produced annually from dairy cows. The average milk production per cow per day is 9 and 2.41 for exotic breeds and local nondescriptive breeds, respectively (Mitiku 2017). Crop residues, enset (false banana), improved forages, wheat bran, concentrates, and natural forages constitute the main feed sources for livestock production (Mitiku 2018).

\section{Study design}

The questionnaire-based cross-sectional study design was conducted from November 2020 to February 2021 in the Kembata Tambaro zone, southern Ethiopia.

\section{Sampling technique and sample size determination}

Two districts were sampled from the study area (i.e., Kedida Gamela and Kacha Bira districts). Both districts were selected based on their dairy production potential and easy access to Durame town (the zone's capital). Four PAs were sampled randomly from the study districts (two from rural administrations and two from towns). Agriculture in rural PAs is characterized as a mixed farming system where both cattle rearing and crop production are equally practiced, whereas agriculture in the town administrations is semi-intensive where animals stay indoors. A total of 278 respondents were interviewed in this study. The sample size was determined by using the formula $\left(n=0.25 / \mathrm{SE}^{2}\right)$ at a standard error (SE) of 0.03 with a 95\% confidence interval (Arsham et al. 2007). The selection of respondents was based on the ownership of at least one dairy cow and on the willingness of the farmer to participate in the study.

\section{Data collection/questionnaire}

A structured questionnaire comprising both closed-and open-ended questions was designed to collect data during the interview. The questionnaire was developed in English, and researcher conducted interviews in the local language (Kambaatissa). One animal health assistant and a traditional healer were interviewed regarding the local names of the major RDs of dairy cows. The questionnaire was pretested on 14 livestock farmers (5\%) to ensure that the objective of the study was clear to respondents, to improve the clarity of questions, and to determine the time needed to complete the survey per participant (Perneger et al. 2015).

The questionnaire contained two parts. The first part included questions about sociodemographic characteristics, such as age, sex, current address, occupation, and level of education. The second part of the questionnaire assessed LFs' knowledge on RDs in dairy cows with a focus on the infectious causes and their preventive practices.
Two modules containing 17 questions on knowledge (K1-K17) and 16 questions on preventive practices (P1P16) were designed in depth. Farmers' knowledge of RSIs, potential means of transmission between animals, information on practices posing a risk of acquisition of the disease in humans, and control practices at farm and within household were assessed in detail through (Table 2). One open-ended question was used to assess the opinion of LFs on the treatment of RDs in their herds.

Each question on knowledge contains $1=$ Yes" and "0 = No" alternatives. Participants who scored above the mean score were considered knowledgeable. Similarly, respondents' preventive practices were assessed by question with " $1=$ agree" and " $0=$ disagree" options. Participants who scored above the mean score were considered to have good preventive practices.

\section{Data analysis and interpretation}

Data collected from the questionnaire were checked for completeness and analyzed using Statistical Package for Social Sciences (SPSS) software V. 20.0 (SPSS Inc., Chicago, IL, USA). Descriptive statistics such as frequencies and percentages were used to summarize the demographic characteristics of respondents and survey findings. Bivariate analysis was used to identify factors associated with outcome variables. Variables that had a $P$ value less than 0.2 in the bivariate analysis were fitted to a multivariable logistic regression model. Odds ratio (OR) estimates were used to determine the degree of association between knowledge and preventive practices of respondents with RSIs. Confidence levels at 95\% were calculated in all the analyses, and a $P<0.05$ was used as a statistical significance level.

\section{Abbreviations}

BA: Birhanu Ayele; BVD: Bovine virus diarrhea; IBR: Infectious bovine rhinotracheitis; NGO: Nongovernment organization; OR: Odds ratio; PA: Peasant association; RDs: Reproductive disorders; RSIs: Reproductive system infections; LFs: Livestock farmers; SL: Samson Leta; SE: Standard error

\section{Acknowledgments \\ The authors are thankful for the technical and practical support they receive from the Livestock and Fishery Development Office of Kembata Tambaro zone.}

\section{Authors' contributions}

B.A.: Contributed to conception of the research idea, designing and data collection, data analysis, interpretation of data, writing and editing of the manuscript. S.L.: Contributed to the editing of the manuscript. Both authors read and approved the final manuscript.

\section{Funding}

The present study received financial support from Wachemo University, Vice President for Research and Development Office.

Availability of data and materials

Data will be shared upon request by the readers. 


\section{Declarations}

\section{Ethics approval and consent to participate}

Ethical clearance was obtained from Wachemo University Durame Campus. Written and oral consent was obtained from livestock farmers before the questionnaire survey.

\section{Consent for publication}

Not applicable.

\section{Competing interests}

The authors declare that they have no competing interests.

\section{Author details}

${ }^{1}$ Department of Animal Science, Wachemo University Durame Campus, Durame, Ethiopia. ${ }^{2}$ College of Veterinary Medicine \& Agriculture, Addis Ababa University, Bishoftu, Ethiopia.

Received: 30 May 2021 Accepted: 7 July 2021

Published online: 18 August 2021

\section{References}

Abutarbush, Sameeh M. 2010. Veterinary medicine-a textbook of the diseases of cattle, horses, sheep, pigs and goats. The Canadian Veterinary Journal 51 (5): 541.

Ahmed, Mohamed A.M., Simeon Ehui, and Yemesrach Assefa. 2004. Dairy development in Ethiopia. EPTD discussion papers 123, International Food Policy Research Institute (IFPRI).

Arif, S., Hernandez-Jover M. ThomsonPC, McGill DM, H.M. Warriach, and J. Heller. 2017. Knowledge, attitudes and practices (KAP) relating to brucellosis in smallholder dairy farmers in two provinces in Pakistan. PLoS One 12 (3): 1-19. e0173365. https://doi.org/10.1371/journal.pone.0173365.

Arsham, Hossein, Deborah Ford, Joel Morse, and Dennis Pitta. 2007. The Rate Decision: Adjustable vs Fixed Rate Mortgages. Journal of Business \& Economics Research (JBER) 5 (11): 31-42. http://home.ubalt.edu/ntsbarsh/ Business-stat/opre504.htm

Ayele, B., W. Tigre, and B. Deresa. 2016a. Investigation of major cattle production constraints in Kembata Tambaro zone of Southern Ethiopia using participatory epidemiology methods. Tropical Animal Health and Production 48 (1): 109-115 https://doi.org/10.1007/s11250-015-0928-y.

Ayele, B., W. Tigre, and B. Deressa. 2016b. Epidemiology and financial loss estimation of blackleg on smallholder cattle herders in Kembata Tambaro zone, Southern Ethiopia. Springerplus 5 (1): 1822 https://doi.org/10.1186/s4 0064-016-3541-2

Cecilia, W., A. Salvatory, and S.L. Susanna. 2019. Ugandan cattle farmers' perceived needs of disease prevention and strategies to improve biosecurity. BMC Veterinary Research 15 (1): 208 https://doi.org/10.1186/s12917-019-1961-2.

CSA. 2020. Agricultural Sample Survey, 2019/20 (2012EC), Volume II: Report on Livestock and livestock characteristics (Private peasant holdings), 2020. Addis Ababa: Central Statistical Agency (CSA), Federal Democratic Republic of Ethiopia.

DI 'ez, J.G., and A.C. Coelho. 2013. An evaluation of cattle farmers' knowledge of bovine brucellosis in northeast Portugal. Journal of Infection and Public Health 6 (5): 363-369 https://doi.org/10.1016/j.jiph.2013.04. 008 PMID: 23999332.

Ettinger, S.J., E.C. Feldman, and E. Cote. 2017. Textbook of Veterinary Internal Medicine-eBook, vol. 2, 8th ed. Philadelphia: Elsevier Health Sciences.

Hussien, AK. 2019. Introductory chapter: Bacterial cattle diseases-economic impact and their control [Internet]. [cited 30 December 2015].

Jansen, J., C.D.M. Steuten, R.J. Renes, N. Aarts, and T.J.G.M. Lam. 2010. Debunking the myth of the hard-to-reach farmer: Effective communication on udder health. Journal of Dairy Science 93 (3): 1296-1306. https://doi.org/10.3168/ jds.2009-2794.

Legesse, Mengistu, Girmay Medhin, Mekonnen Bayissa, and Gezahegne Mamo. 2018. Knowledge and perception of pastoral community members about brucellosis as a cause of abortion in animals and its zoonotic importance in Amibara district, Afar Region, Ethiopia. PLoS One 13 (11): e0206457. https:// doi.org/10.1371/journal.pone.0206457.

McDermott, John, and Delia Grace. 2012. Agriculture-associated diseases: adapting agriculture to improve human health. Edited by Shenggen Fan and Rajul Pandya-Lorch: 103.
Mitiku, M. 2017. Status of Brucellosis occurrence and Its Association with Reproductive Disorders in Dairy cattle at Kembata Tembaro Zone, SNNPR ETHIOPIA. MSC thesis in Veterinary Epidemiology. Hawassa: Hawassa University.

Mitiku, Mulatu. 2018. Major Reproductive Health Problems in Small Holder Dairy Farms in and Around Durame Town, Southern Ethiopia. J Vet Med Res 5 (9): 1158.

Ndengu, Masimba, M. De Garine-Wichatitsky, Davies Mubika Pfukenyi, M. Tivapasi, B. Mukamuri, and Gift Matope. 2017. Assessment of community awareness and risk perceptions of zoonotic causes of abortion in cattle at three selected livestock-wildlife interface areas of Zimbabwe. Epidemiology \& Infection 145 (7): 1304-1319. https://doi.org/10.1017/S0950268817000097.

Overbay, Thomas D. 1999. Venereal Diseases in the Bull. J Bullish on Quality Beef 72-76;VA: 24201

Perneger, T.V., D.S. Courvoisier, P.M. Hudelson, and A. Gayet-Ageron. 2015. Sample size for pre-tests of questionnaires. Quality of Life Research 24 (1): 147-151. https://doi.org/10.1007/s11136-014-0752-2.

Radostitis, OM Blood., D.C. Gay, C.C. Hinchcliff, and KW. 2000. London: Veterinary medicine, 8th ed. London: Bailliere Tindal.

Radostits, Otto M., C.C. Gay, Kenneth W. Hinchcliff, and Peter D. Constable. 2007. A textbook of the diseases of cattle, horses, sheep, pigs and goats. 9th ed. London: Veterinary medicine. W.B. Saunders Company Ltd..

Roberts, S.J. 1971. Veterinary Obstetrics and Clinical Diseases (Theriogenology) Published by the Author, 496-506. Ithaca.

Rosales, Eduardo Barahona, and Burim N. Ametaj. 2021. Reproductive Tract Infections in Dairy Cows: Can Probiotics Curb Down the Incidence Rate? Dairy 2 (1): 40-64. https://doi.org/10.3390/dairy2010004.

Softic, Adis, Adam Dunstan Martin, Eystein Skjerve, Nihad Fejzic, Teufik Goletic, Aida Kustura, and Erik Georg Granquist. 2020. Reproductive Performance in a Selected Sample of Dairy Farms in Una-Sana Canton, Bosnia and Herzegovina. Veterinary Medicine International VI: 2190494. https://doi.org/1 $0.1155 / 2020 / 219049$

Sprott, L.R. Field, and W. Robert. 2012. "Reproductive diseases in cattle." Texas Agriculture Extension Service. Texas A\&M University System.

Subhash, Chand, B.S. Meena, K.S. Kadian, and Singh Anoop. 2013. Knowledge of dairy farmers on reproductive disorders of dairy animals. Veterinary Practitioner 14 (1): 23-25.

Vaarst, Mette, D.K. Byarugaba, J. Nakavuma, and C. Laker. 2007. Participatory livestock farmer training for improvement of animal health in rural and periurban smallholder dairy herds in Jinja, Uganda. Tropical Animal Health and Production 39 (1): 1-11. https://doi.org/10.1007/s11250-006-4439-8.

van Bree, Freek P.J., Gertie C.A.M. Bokken, Robin Mineur, Frits Franssen, Marieke Opsteegh, Joke W.B. van der Giessen, Len J.A. Lipman, and Paul A.M. Overgaauw. 2018. Zoonotic bacteria and parasites found in raw meat-based diets for cats and dogs. Veterinary Record 182 (2): 50-50. https://doi.org/1 0.1136/vr.104535

Velázquez-Ordoñez, Valente, Benjamín Valladares-Carranza, Esvieta TenorioBorroto, Martín Talavera-Rojas, Jorge Antonio Varela-Guerrero, Jorge AcostaDibarrat, Florencia Puigvert, Lucia Grille, Álvaro González Revello, and Lucia Pareja. 2019. Microbial contamination in milk quality and health risk of the consumers of raw milk and dairy products. Nutrition in Health and DiseaseOur Challenges Now and Forthcoming time. https://doi.org/10.5772/ intechopen.86182.

World Bank. 2010. People, pathogens, and our planet: Volume one - towards a one health approach for controlling zoonotic diseases. World Bank. @ World Bank https://openknowledge.worldbank.org/handle/10986/2844 License: CC BY 3.0 IGO. http://hdl.handle.net/10986/2844

Yoo, Han Sang. 2010. Infectious causes of reproductive disorders in cattle. Journal of Reproduction and Development 56 (S): S53-S60. https://doi.org/10.1262/ jrd.1056S53.

Zewdie, Wubishet, E. Wario, and A. Tehetna. 2018. Assessment of Community Awareness on Common Zoonotic Disease in and around Yabello District of Oromia Regional State, Ethiopia. Multidisciplinary Advances in Veterinary Science 2 (4): 388-394.

Zhang, Ning, Hao Zhou, De-Sheng Huang, and Peng Guan. 2019. Brucellosis awareness and knowledge in communities worldwide: A systematic review and meta-analysis of 79 observational studies. PLoS Neglected Tropical Diseases 13 (5): e0007366. https://doi.org/10.1371/journal.pntd.0007366.

\section{Publisher's Note}

Springer Nature remains neutral with regard to jurisdictional claims in published maps and institutional affiliations. 